\title{
Images of self and others as computer users: the role of gender and experience
}

\author{
E. M. Mercier, B. Barron \& K. M. O'Connor \\ School of Education, Stanford University, Stanford, CA, USA
}

Abstract

Keywords
Gender differences in the pursuit of technology careers are a current issue of concern. We report on two studies that use surveys, drawings and interviews to examine sixth- and eighthgrade students' perceptions of knowledgeable computer users and their self-perception as a computer-type person. In Study 1, participants were asked to generate representations of computer users in pictures or words. The results indicate that the majority of representations were of male users and they frequently wore glasses. Students of both genders were more likely to draw males. Eighth-grade students' representations included more stereotypical features than those of sixth-grade students. In Study 2, students were asked whether they believed that there was such a thing as a computer-type person and whether they perceived themselves to be one. Eighty per cent of students rejected this characterization. They differed from students who accepted it in their levels of past experience, their confidence, and the probability that they shared their knowledge with others. The results of both studies suggest that while there is a male image of computer science in general, it is not overly negative and students' self-perception is not governed by their own gender as much as by other variables.

digital divide, ecological perspectives, gender, identity, stereotypes, technology.

\section{Introduction}

In 1957, the anthropologist Margaret Mead and her colleague Rhoda Métraux published a study in Science that examined students' attitudes towards scientists. They asked male high-school students to write a paragraph beginning, 'If I were going to be a scientist, I would like to be the kind of scientist who ...' Female students could choose to answer the above question, or could finish the sentence 'If I were going to marry a scientist, I would like to marry the kind of scientist who ...' Their interest was in the image of the scientist, not only in the abstract but in relation to one's own possible future life - as practitioner or mate. This special issue asks whether there is a gender digital divide, which in many ways is asking how much have

Accepted: 5 May 2006

Correspondence: Emma M. Mercier, School of Education, Stanford University, Stanford, CA, USA. E-mail emercier@stanford.edu things changed in the last 50 years? Do current research efforts suggest that male students are more likely to be the future scientists, the innovators, and the more knowledgeable users of technology? This paper describes two studies that use drawings, interviews, and surveys to determine whether we still see gender differences in attitudes towards technology, and to understand these attitudes, not only as an abstract concept but also in relation to students' sense of self.

Concerns about equity in relation to technology have existed since computers became a commercially available resource. The digital divide was initially defined with respect to physical access to computers. However, as we enter the 21 st century, access issues, in post-industrial societies at least, are becoming less of an issue. Instead, the discourse has shifted to emphasize how computers are used (Warschauer 2003) and what learning opportunities people of different 
demographic groups have that will help them become empowered users and perhaps even designers of new technologies (Barron 2004).

Patterns of participation in higher education make it clear that men and women differentially pursue majors in computer science, and women are less likely to be represented in careers that involve computing. Inequitable participation in computer science fields has been documented at all levels in most Western nations, with few females engaging in technologyrelated courses in high school and college and fewer continuing to advanced degrees and jobs in the computer industry. This pattern has been referred to as the Incredible Shrinking Pipeline (Camp 1997). The Organization for Economic Co-operation and Development (2002) reports that females make up less than a third of students who graduate with an undergraduate computer science degree in OECD countries.

Several studies have examined why females are less likely to pursue computer science, and why they do not persist in the discipline (e.g. Jagacinski et al. 1988; Sackrowitz 1995; Margolis \& Fisher 2002). Some reasons listed by Lazowska (2002) are the isolation associated with the field, inability to see the relevance of highly theoretical basic courses, negative experiences in laboratory courses, unpleasant classroom climates and a lack of role models. Other reports include a simple lack of interest and unflattering negative stereotypes of those who use computers heavily (American Association of University Women Educational Foundation 1999; Schott \& Selwyn 2000).

Identifying as a member of a discipline has been noted as an important factor in persistence in mathematics, engineering and certain science fields, disciplines that have a gender composition similar to computer science (Packard \& Wong 1999; Teague 2002). Identification with a discipline is partly the result of how one perceives other people within that discipline and an appraisal of whether one is or is not like them. For this reason, it seems important to understand students' stereotypes of computer users to illuminate how they perceive the characteristics of technology users and their own roles in relation to technology. In particular, it is important to assess these attitudes and perceptions early on, when students first begin to have choice in their course of study in school.

Stereotypes have been defined as 'a set of beliefs about the personal attributes of a group of people'
(Ashmore \& Del Boca 1981, p. 16). The phenomenon of stereotyping has been described in terms of category formation and attributed to the general tendency of humans to reduce the cognitive complexity they encounter in the world. Stereotypes are theorized to result from complex societal forces including political and historical situations and are conveyed through face-toface interactions as well as print and electronic media. Stereotypes have been shown to lead to biases in information processing, influence expression of polite behaviour, influence performance by invoking a threat of confirming a negative stereotype (see Fiske 1998 for a review), and influence appraisals of the self with respect to a sense of 'fit' with an activity or occupation (Packard \& Wong 1999). Concern over the damaging influence of stereotypes has motivated numerous studies that elicit and look for effects of stereotypes in a wide range of decision-making situations and within performance contexts such as achievement tests (Steele 1997). More specifically, the male computer 'nerd' seems to be a prominent stereotype in Western culture, showing up in films like Office Space and Bedazzled, and even in the action figure GeekMan, a plastic doll created by Happy Worker Inc. This stereotype includes attributes such as being male, wearing glasses, and being antisocial or not attractive to women.

One way in which social scientists have elicited stereotypical images is by asking students to draw or describe a certain kind of person. For example, in the Mead and Métraux (1957) study, high-school students were asked to write an essay about the desired or feared attributes of a scientist that they may become (or be married to). They found several common themes including the view that the work of the scientist is somewhat undesirable because it involves danger, working for long hours without reward, and a developmental trajectory in which one becomes more isolated and out of touch with the average person. The draw-a-person test was developed originally in the 1920s to assess intelligence (Goodenough 1926), and was later used for the assessment of children's emotional functioning (Harris 1964) and attitudes towards professions such as science (Chambers 1983) and engineering (Knight \& Cunningham 2004). Barba and Mason (1994) report on a study where they examined age and gender differences in the drawings of computer users, finding the development of a 'nerd' figure as students got older. These 'nerd' images were male 
and included glasses, pocket protectors, a thin body, and a pale complexion from too much time indoors. We found similar images from 12th graders at a high school in Northern California (Barron et al. 2003), with some depicting computer scientists who fit closely with this 'nerd' description. While these general images tell us something about culturally shared images of certain groups of people, they do not necessarily tell us about how any particular students judge themselves in relation to a prototypical member of a group that is thought to share some set of features. Our research attempts to begin to understand the relationship between personal experience and perceptions of what it means to be knowledgeable.

Based on our earlier research that documents the important relationship between students' history of experience and their engagement, confidence, and learning resources (Barron 2004), we hypothesized that there would be larger differences within gender groups than between them and that students' selfperceptions would be tied to their personal experience with computers and their access to learning opportunities across the settings of home, school, and community. This conceptualization of learning opportunities as a system has led to a learning ecologies framework where a learning ecology is defined in terms of the set of contexts, comprised of activities, material resources, and relationships that are found in physical or virtual spaces that provide opportunities for learning (Barron 2004, in press). This view emphasizes the importance of understanding students' particular life contexts and the specific relationships and activities they are involved in to understand their perceptions of others and themselves in relation to computing. To operationalize history of experience, we have focused on fluency-building activities (as defined by the National Research Council 1999) because of our assumption that participation in these creative activities, where students make something with the technology, is more likely to be related to a perception of oneself as a competent and knowledgeable computer user than activities such as games or information seeking.

In our paper, we share two studies that investigate the issues of stereotypes and perceptions of the self. We studied middle-school students' perceptions of those who are knowledgeable about computers. In the first study, we ask students to imagine a knowledge- able computer user and to provide a drawing or written representation of that person. These representations were then coded and analysed as a function of both the gender and the grade of the student. In the second study, we ask students to give their opinion about whether there are types of people who are computertype people and, if so, what they are like. We also ask them whether they see themselves as computer-type people. Their self-identification is then used as the basis for comparing students on a number of dimensions including their prior experience with technology, their confidence in using technology, their engagement in learning about computers, and whether they teach others about technology. Like Mead and Métraux (1957), we were interested in the images that students have, both with respect to a relatively abstract group of people identified as knowledgeable and with respect to the self.

\section{Method}

\section{Sample}

Participants were drawn from two middle schools 10 miles apart in Northern California. Middle school is a 3-year school that students attend between sixth and eighth grade, within the US school system; students in middle school are generally between 10 and 14 years of age. Sixth graders were surveyed and interviewed during the autumn and eighth graders participated at the end of spring. In this way, our sample gave a crosssectional picture of students as they entered and left middle school. Eighty-one sixth graders and 83 eighth graders from Maple Middle School participated in the study. Sixty-four sixth graders and 77 eighth graders from Juniper Middle School participated in the study.

All 145 sixth graders and 160 eighth graders who participated in the studies were surveyed. Of these 305 students, 102 sixth graders and 126 eighth graders responded to the item asking them to draw or describe a computer user (Study 1). Fifty-three sixth graders and 68 eighth graders, a subset of those who were surveyed, were interviewed as part of Study 2 .

\section{Instruments}

The instruments included a survey and an interview. Students completed the Access, Interest, and Experi- 
ence Survey, designed by the second author for use in another study (Barron et al. in press). This survey includes Likert-response items, checklists, and openended questions. The closed-response questions were designed to tap into five main areas: (1) students' access to technology at home and school; (2) students' history of technology use across communicative, entertainment, learning, and fluency-building activities; (3) students' use of formal and informal learning resources; (4) students' motivation to learn about computing; and (5) students' sharing of knowledge with others. This study examines items that focus on students' experiences with 16 fluency-building activities, whether they have taught others about computers, and their engagement in learning about computers and confidence with computers. The items are listed in Appendix A. The open-ended items included the projective drawing item that is the focus of Study 1. Students were asked to 'Close your eyes and imagine someone who really knows a lot about computers and how to use them. After you have an image in mind, please draw and/or describe what this person looks like'. Students completed their depiction within the survey booklet using their own pens or pencils.

Semi-structured interviews were designed to prompt elaborations on the items accessed through the survey. In Study 2, we focus on a subset of questions, specifically, 'Is there a computer-type person?' and 'Are you a computer-type person?'

\section{Procedures}

Students were asked to complete the survey during a normal class period. Researchers were present to answer any questions. The survey took $40 \mathrm{~min}$ to complete. A subset of the students was interviewed during this same period or during a subsequent class period. Interviews lasted between 15 and $30 \mathrm{~min}$.

\section{Results}

\section{Study 1: depictions of someone who uses a computer}

Depictions were coded as drawings, descriptions, or both. We coded depictions for the gender of the depiction and whether there were glasses, a lab coat, or a pocket protector in the depictions. Additionally, descriptions were coded for abnormal body weight, pale skin, negative personality characteristics, antisocial behaviour, and use of the term 'nerd'. For analysis, the negative personality characteristics and antisocial behaviour categories were collapsed to form a single variable of negative personality characteristics. The coding scheme was initially developed by coding all characteristics in a set of drawings (Barron et al. 2003) and then eliminating, or collapsing across categories, when characteristics appeared infrequently. Definitions and examples of representations that reflect each code are provided in Appendix B. Two of the authors coded the depictions with a reliability of over $90 \%$ on each code. Thirty-seven per cent of responses were drawings, 23\% were descriptions, and 40\% included both drawings and descriptions. (A description was defined as one or more words.) There were no differences between the types of representations that male and female students depicted.

\section{Gender of knowledgeable computer users}

The gender of the representations was coded as male, female, or ambiguous (i.e. when the gender of the drawing was indistinguishable or when the students used gender-neutral pronouns in their descriptions). Two per cent of representations were coded as 'both' but for the statistical analysis, the 'both' and 'ambiguous' categories were collapsed.

Prior research has shown that in the draw-a-persontest, students are more likely to represent their own gender (Goodenough 1926). However, in the drawa-scientist test (Chambers 1983) and the drawa-computer-user test (Brosnan 1999), it is reported that more male depictions are produced by both male and female students. Twenty-one per cent of females depicted female computer users $(60 \%$ depicted males and $19 \%$ were ambiguous) and $56 \%$ of males depicted male computer users $(6 \%$ depicted females and $38 \%$ were ambiguous). This difference is statistically significant, $\chi^{2}(2, N=228)=17.46, P<0.001$.

In Table 1, we see the results from our sample, broken out by grade and gender of student. Chi-square analysis indicated that there was a significant difference in what sixth and eighth graders depicted, $\chi^{2}(2$, $N=228)=16.22, P<0.001$. While both grades depicted about the same number of male computer users, sixth graders depicted a higher percentage of female computer users than eighth graders. A higher 
Table 1. Percentages of depictions of computer users of each gender by sixth- and eighth-grade students.

\begin{tabular}{llll}
\hline Gender of depiction & \multicolumn{2}{c}{ Gender of student } & \multirow{2}{*}{ All students } \\
\cline { 2 - 3 } & Male & Female & \\
\hline Sixth grade $(n=102)$ & & & \\
$\quad$ Male & 62 & 53 & 57 \\
Female & 10 & 33 & 24 \\
Ambiguous & 29 & 13 & 20 \\
Eighth grade $(n=126)$ & & & \\
Male & 52 & 67 & 60 \\
Female & 3 & 10 & 6 \\
$\quad$ Ambiguous & 44 & 24 & 34 \\
\hline
\end{tabular}

percentage of eighth-grade depictions were coded as ambiguous than sixth-grade ones.

At both grade levels, there was a significant difference between male and female students in the genders that they depicted. In the sixth-grade sample, more female students than male students produced representations coded as female computer users. More male students than female students depicted computer users that were coded as ambiguous, $\chi^{2}(2, N=102)=$ $9.19, P<0.01$. The pattern was similar for the eighthgrade students, $\chi^{2}(2, N=126)=7.01, P<0.05$.

\section{Stereotypical characteristics}

Certain characteristics seem to draw on a cultural stereotype of a computer user. We coded students' depictions of computer users for the presence of stereotypical features. These features, and the percentages of representations that included each of them are shown in Table 2. As can be seen, the most commonly depicted stereotypical features coded were a male gender and a person wearing glasses. A small percentage of representations included the label of nerd or indicated negative personality characteristics.

In order to see whether there was any clustering of features, we created a composite variable for students who depicted two or more stereotypical features. The most frequent pairing was a male with glasses. Of the 70 depictions with two or more stereotypical features, $89 \%$ were male and $94 \%$ had glasses. The remaining six depictions that included glasses were coded as ambiguous and contained at least one other stereotypical feature (e.g. negative social characteristics, abnormal weight, the term 'nerd'). In general, glasses
Table 2. Stereotypical features in students' depictions of computer users.

\begin{tabular}{lcc}
\hline & $\begin{array}{l}\text { Per cent of } \\
\text { depictions }\end{array}$ & $\begin{array}{c}\text { Number of } \\
\text { depictions }\end{array}$ \\
\hline Features found in both drawings and & written depictions $(n=228)$ \\
Glasses & 34.2 & 78 \\
Lab coat & 0.4 & 1 \\
Pocket protector & 2.6 & 6 \\
Male gender & 58.3 & 133 \\
Features found only in written depictions $(n=144)$ & \\
Pale complexion & 1.4 & 2 \\
Nerd & 6.3 & 9 \\
Negative social characteristics & 2.8 & 4 \\
Abnormal body weight & 2.8 & 4 \\
\hline
\end{tabular}

were included in $45 \%$ of male depictions, $16 \%$ of female depictions, and $21 \%$ of ambiguous depictions, a statistically significant difference, $\chi^{2}(2, N=228)=$ $17.09, P<0.001$. Some examples of these are provided in Fig 1; Fig 2 shows examples that have no stereotypical features.

Twenty-six per cent of sixth graders and 33\% of eighth graders included two or more stereotypical characteristics in their representation. As can be seen in Table 3, there were no gender differences at eighth grade, $\chi^{2}(1, N=126)=0.04$, NS, but the difference was significant at sixth grade, $\chi^{2}(1, N=102)=7.2$, $P<0.01$, with male sixth graders depicting two or more stereotypical images more often than females.

\section{Study 2: students' perceptions of themselves as computer users}

Interviews were carried out with 53 sixth-grade and 68 eighth-grade students. In this section, we report analyses of their responses to the questions of whether they believed there was such a thing as a computertype person, and whether they considered themselves to be computer-type people. Responses were coded for immediate response and elaborations by two coders, with over $90 \%$ reliability on each code. The codes for the interview questions are shown in Appendix C.

Seventy-eight per cent of males and $75 \%$ of female students said that there was such a thing as a computer-type person. We coded for three common explanations for why a person would be considered a computer-type person: knowledge, time, and motivation explanations. Thirty-two per cent of students did 


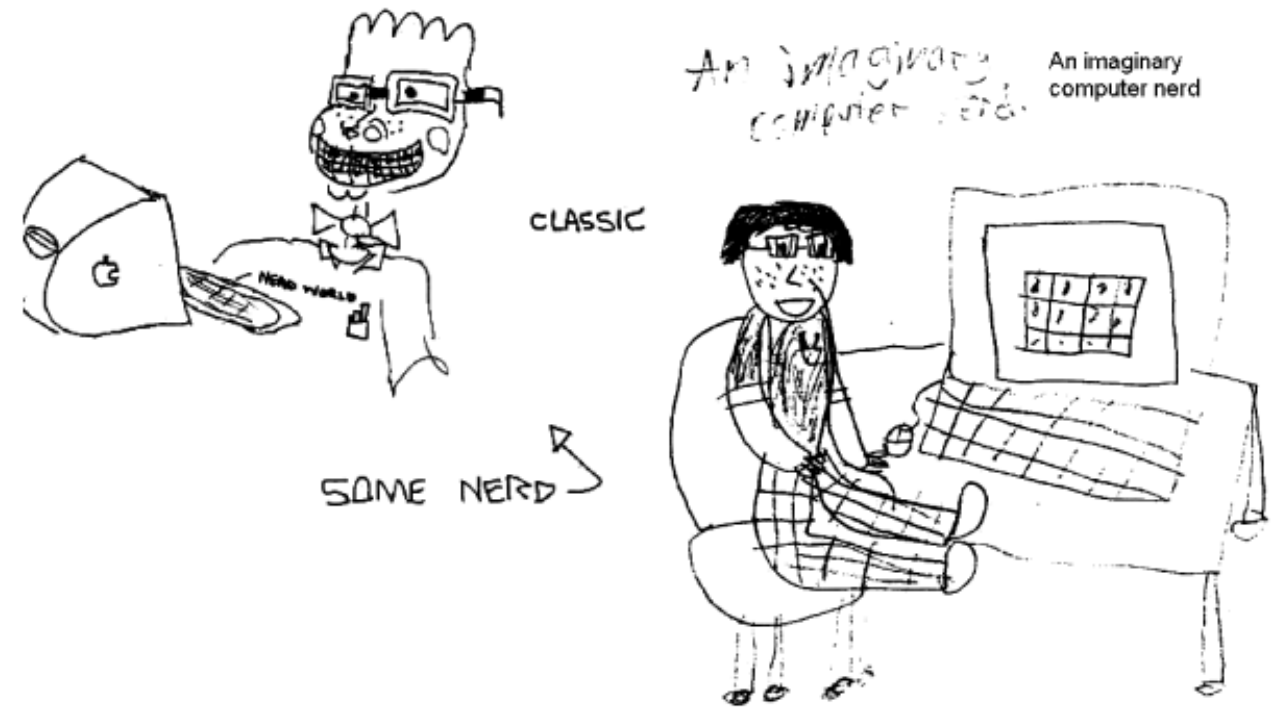

Fig 1 Depictions with many stereotypical characteristics.
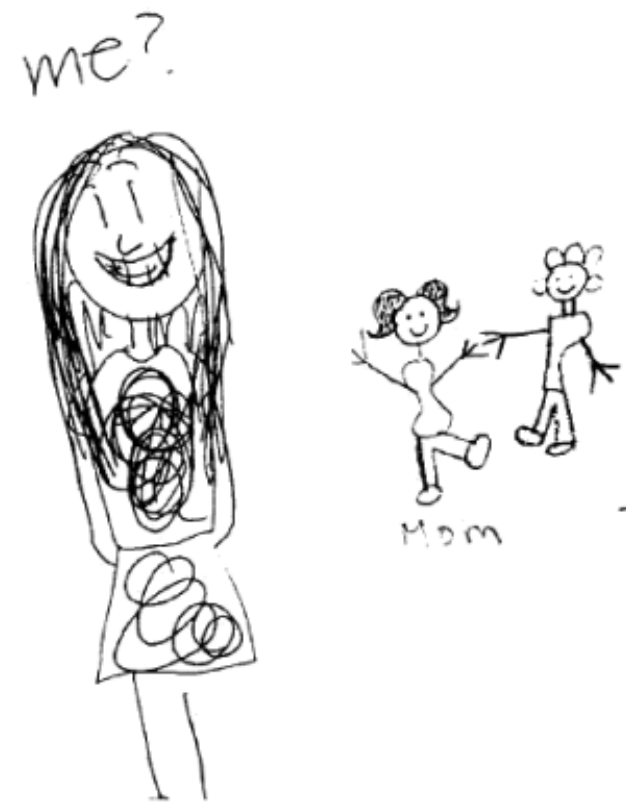

Pad

Fig 2 Depictions with few stereotypical characteristics.

Table 3. Percentage of students in sixth and eighth grades depicting two or more stereotypical features.

\begin{tabular}{llll}
\hline Grade level & $\begin{array}{l}\text { Male } \\
\text { students }\end{array}$ & $\begin{array}{l}\text { Female } \\
\text { students }\end{array}$ & $\begin{array}{l}\text { All } \\
\text { students }\end{array}$ \\
\hline Sixth grade & 41 & 16 & 26 \\
Eighth grade & 33 & 33 & 33 \\
\hline
\end{tabular}

They are both computer engineers

not give an explanation, $43 \%$ gave one, $18 \%$ gave two, and $7 \%$ gave three. Thirty-nine per cent of responses used a knowledge explanation, saying that someone who is a computer-type person knows a lot about computers. Thirty-three per cent of students said that someone who spends a lot of time with computers is a computer-type person, and $27 \%$ of students gave a motivation explanation, saying that someone who loves computers is a computer-type person. 
All students, regardless of their answer to the is there a computer-type person' question, were asked the question 'are you a computer-type person?' Answers were coded as either yes, no, or maybe. Table 4 shows that the majority of students did not believe that they were computer-type people. More than twice as many eighth graders saw themselves as computer-type people than sixth graders, and twice as many sixth graders said that they might be computer-type people as eighth graders. The association between grade and response was statistically significant, $\chi^{2}(2$, $N=86)=6.35, P<0.05$.

There were no statistical differences between the responses of male or female students, $\chi^{2}(2, N=86)=$ 0.27 , NS. As can be seen in Table 4, there was virtually no difference between male and female responses.

\section{Variables distinguishing students who believe they are or are not computer-type people}

In order to better understand what contributed to differences in students' perceptions that they were, might be, or were not computer-type people, we compared our three groups on a number of variables including their prior experience with fluency-building uses of technology, their overall engagement with learning about computers, their confidence with technology, and whether they taught other people how to use technology. These analyses are reported below.

\section{Fluency-building experiences}

Students were asked to indicate the number of times they had participated in 16 fluency-building activities ranging from creating a multimedia presentation to writing programming code. We created an experience score based on the number of activities students had participated in at least once. An analysis of variance was performed using history of experience as the de- pendent variable, and student's gender and answer to the question 'are you a computer-type person' as independent variables. The results indicated that there was no effect of gender on experience with fluencybuilding activities, $F(1,74)=1.17, P=0.76$. However, there was a significant main effect of one's identification as a computer-type person on total fluency-building activities, $F(2,74)=51.98, P<0.05$. Students who said they were computer-type people had experienced a mean of 9.7 fluency-building activities, those who felt they might be computer-type people had experienced a mean of 7 activities, and those who said they were not computer-type people had experienced a mean of 6.6 activities (SEs $=0.95,0.95$, and 0.49, respectively). Scheffé's post hoc analysis indicates that the difference in the mean number of experiences of the students who said they were computer-type people and the students who said they were not computer-type people was statistically significant.

\section{Teaching others}

We compared the proportion of students who reported teaching others about technology as a function of their endorsement of being a computer-type person. The data presented in Table 5 reflect the fact that at both grades, students who saw themselves as computertype people were more likely to be engaged in teaching others than those who did not think they were computer-type people. The probability of teaching others if one were not sure whether one was a computer-type person differed for sixth and eighth graders. Forty per cent of sixth-grade students who stated that they might be computer-type people reported teaching others as did $80 \%$ of eighth graders. This association between teaching others and self-perception was significant for eighth graders, $\chi^{2}(2, N=46)=8.68$, $P<0.05$, but not for sixth graders, $\chi^{2}(2, N=37)$ $=1.47, \mathrm{NS}$.

Table 4. Percentage of student responses to 'Are you a computer-type person?' question.

\begin{tabular}{|c|c|c|c|c|}
\hline \multirow[t]{2}{*}{ Response } & \multicolumn{2}{|l|}{ Grade level } & \multicolumn{2}{|c|}{ Gender of student } \\
\hline & Sixth grade $(n=38)$ & Eighth grade $(n=48)$ & Male $(n=38)$ & Female $(n=48)$ \\
\hline Computer-type person & 10.5 & 25.0 & 21.1 & 16.7 \\
\hline May be computer-type person & 29.0 & 10.4 & 18.4 & 18.8 \\
\hline Not computer-type person & 60.5 & 64.6 & 60.5 & 64.6 \\
\hline
\end{tabular}


Table 5. Percentage of students who teach others by responses to 'Are you a computer-type person?' question.

\begin{tabular}{llll}
\hline \multirow{2}{*}{ Grade level } & \multicolumn{2}{l}{ Response } & \\
\cline { 2 - 4 } & Yes & Maybe & No \\
\hline Sixth grade & 75 & 40 & 48 \\
Eighth grade & 92 & 80 & 45 \\
\hline
\end{tabular}

Fifty-three per cent of sixth-grade males and $63 \%$ of sixth-grade females reported teaching at least one person about computers. Sixty-one per cent of eighthgrade males and $64 \%$ of females reported teaching at least one person. Chi-square analysis indicated that the association between gender and teaching others was not statistically significant at either sixth grade, $\chi^{2}(2, N=144)=1.41, \mathrm{NS}$, or eighth grade, $\chi^{2}(2, N=$ $151)=0.13$, NS.

\section{Engagement in learning about computers and confidence}

Eight Likert-scale items were designed to assess students' attitudes towards computers. Students answered on a five-point scale from disagree strongly (1) to agree strongly (5). Five of these items were combined to create a measure of engagement and three were combined to create a measure of confidence. The engagement scale had a reliability $\alpha$ of 0.82 , and the confidence scale had an $\alpha$ of 0.89 . The survey items for these scales are provided in Appendix A.

A multivariate analysis of variance was performed using the engagement and confidence scales as the dependent variable and gender and the students' answers to 'are you a computer-type person' as the independent variables. Results indicated that there was a main effect of being a computer-type person on confidence, $F(2,64)=6.27, P<0.01$. The effect of selfidentification as a computer-type person on engagement approached statistical significance, $F(2,64)=2.14$, $P=0.056$. The effect of gender and the gender by computer-type person interactions were not statistically significant. For the confidence scale, Scheffé's post hoc analysis indicated that there was a statistical difference in mean confidence ratings between students who said they were not computer-type people and those who said that they might be, and between those who said they were not and those who said that
Table 6. Mean engagement and confidence scores by response to 'Are you a computer-type person?' question.

\begin{tabular}{|c|c|c|c|c|c|c|}
\hline \multirow[t]{3}{*}{ Scale } & \multicolumn{6}{|c|}{ Response } \\
\hline & \multicolumn{2}{|l|}{ Yes } & \multicolumn{2}{|c|}{ Maybe } & \multicolumn{2}{|l|}{ No } \\
\hline & $\begin{array}{l}\text { Mean } \\
\text { score }\end{array}$ & $\mathrm{SE}$ & $\begin{array}{l}\text { Mean } \\
\text { score }\end{array}$ & $\mathrm{SE}$ & $\begin{array}{l}\text { Mean } \\
\text { score }\end{array}$ & SE \\
\hline Engagement & 4.13 & .23 & 4.17 & .27 & 3.62 & .12 \\
\hline Confidence & 4.41 & .25 & 4.40 & .30 & 3.51 & .14 \\
\hline
\end{tabular}

they were computer-type people. The data presented in Table 6 suggest that students who said they were not computer-type people scored lower on this scale. The means in Table 6 indicate that the students who said they were computer-type people had the highest confidence score, followed by those who said maybe, and students who said they were not computer-type people had the lowest confidence.

\section{Discussion}

This special issue is devoted to the question of whether or not there is a gender divide with respect to technology use. As we argued in the introduction, the patterns of participation by males and females in computing fields suggest that there is still a gender divide that needs to be addressed. In the research reported in this paper, we investigate whether middleschool students perceive knowledgeable computer users to mirror what seems to be a cultural stereotype of a socially awkward male. The results of Study 1 suggest that the category of knowledgeable computer user is gender marked for middle-school students, and that frequently they represent a male with glasses. We found a small number of images that mirror the fullblown negative stereotype parodied in TV shows such as Alias or in the 'Geek Man' doll. Examining the drawings and descriptions of computer users leads us to the conclusion that there is very little difference in how eighth-grade male and female students and sixthgrade males depict a knowledgeable computer user. The majority of the depictions are of males and about a third contain two or more stereotypical characteristics. The depictions created by the sixth-grade females look different from the rest of the depictions, containing fewer stereotypical characteristics and a higher proportion of females. The results indicate that 
for the majority of the middle-school students in our sample, knowledgeable computer users are male and are likely to have one or more characteristics that are associated with a cultural stereotype.

Our second study asks for perceptions of computer users in another way. We ask students whether they believe that there is such a thing as a computer-type person and if so what that person is like. We find that $75 \%$ of students agree that there is such a category, suggesting that they may hold some kind of stereotype. However, in contrast to the drawings, the answers to the interview question 'Is there a computertype person?' focus on the behaviour or skills of a computer-type person rather than their physical appearance. The majority of students' definitions fall into three categories: motivational, time based, or knowledge based. Students view computer-type people as people who love computers, know a lot about computers, or spend a lot of time using computers. Some students did indicate that the term had a negative connotation, such as the student who said she is a computertype person, but does not want to be thought of as one, or the student who said he is not a 'computer freak'.

Over $60 \%$ of students said that they are not computer-type people, while nearly $19 \%$ said that they are and another $19 \%$ said that they might be computertype people. There are virtually no differences in the percentage of males and females in each category. A higher percentage of eighth-grade students are sure that they are computer-type people than sixth graders, although the same proportion in both age groups said that they are definitely not computer-type people.

To better understand how these three groups differ, we compared them on a number of dimensions including their experience with technology, engagement in learning about computers, confidence with technology, and the likelihood that they are teaching others. As predicted, the differences within each gender are larger than between genders. The results indicate that students who said that they are computer-type people have engaged in more fluency-building activities, are more likely to be teaching others, are more confident with technology, and report higher levels of engagement in learning about technology. Students who state that they might be computer-type people fall between those who say they are and those who say they are not on the teaching others and experience items, and are at almost the same level as students who said they are computer-type people on the confidence and engagement scales. Students who reject this characterization have fewer experiences, are less likely to be teaching others, and report lower confidence and engagement.

Our two studies together provide some evidence that a cultural stereotype of a computer user exists. Study 1 suggests that this category is associated with the male gender. Study 2 indicates that students' views of computer-type people are in fact multidimensional and that enjoyment, interest, time, or knowledge are all markers of this category. The fact that so many students do not see themselves as computer-type people is not evidence that students are rejecting this label due to a desire to avoid a negative image. In fact, many students seem to be making judgements based on comparisons within their social network on dimensions such as expertise or degree of involvement. Additional research might be able to clarify whether becoming a computer-type person is a feared possible self or not.

We suggest some educational implications for the promotion of equal participation for males and females. The first study indicates that there is a cultural stereotype, which the majority of students replicate, that knowledgeable computer users are male, or at least that knowledgeable computer users are not female. There seems to be a slight cohort effect in our results for female students, which is likely to be a developmental effect, with older females being more aware of the cultural stereotype than younger females, although a longitudinal study is necessary to confirm this.

The second study indicates that, although the cultural stereotype is evident in our sample, males and females are equally likely to perceive themselves as computertype people at both grade levels. Experiences with technology, either directly or when teaching others about it, seem to differentiate between students who say they are, might be, or are not computer-type people. Confidence and engagement are high for the students who say that they are computer-type people and for those who say that they might be, perhaps suggesting that students who say that they might be computertype people are aware that they have not had enough experience to endorse that identity. The significant relationship between teaching others and endorsement of being a computer-type person also suggests the role of experience, this time the experience of being an 
expert, in helping students see themselves as computertype people. Taken together, these items indicate the importance of giving students multiple, varied experiences with technology, and ensuring that students have the chance to be both the teacher and the learner in these situations. This suggests the possible value of opportunities for students to work with others who know both more and less than they do.

Using two methods of accessing students' perceptions of knowledgeable computer users (pictorial or verbal representations of visual images and interviews that ask for general characterizations) has allowed us to understand the complex dimensions of the images that students have of computer users. The draw-acomputer-users test has been criticized in the past (O'Maoldomhnaigh \& Mhaolain 1990) because it promotes the depiction of a unidimensional stereotype; however, it has also been argued that because visual images shape the way we think about things, understanding students' images of different professions will give us a better understanding of their attitudes about the disciplines (Knight \& Cunningham 2004). The visualization task clearly accesses a stereotypical image that differs from students' responses when they were asked about a computer-type person during the interview. Coupled with the responses to interview questions, the prominence of the concept of a computer-type person is striking. We now have a greater understanding of why engaging with technology might be less attractive to some students. While the perceived gender of computer users might play a part in determining who engages in technology-related activities, the perception that being a computer-type person means not having other interests, or at least committing a significant amount of time to computing activities, could explain the low self-identification of both males and females. Future research on this topic may use other methods of assessing the presence of stereotypes such as the Implicit Association Test (Greenwald \& Banaji 1995). The developers of this assessment argue that explicitly asking for characterizations of people is likely to underestimate people's actual associations due to their unconscious nature or an unwillingness to endorse them publicly. It would be interesting to use an implicit association test to understand individual differences in the strength of association. Our results would predict that those students with more experience may have weaker associations than those with less experience. Role models that counter the stereotype may also be important.

Our data speak to the stereotypes that students have about computer users and how students see themselves in relation to technology; yet, there are a number of limitations to the studies. Owing to data collection limitations, there was not sufficient overlap in students who were interviewed and who created depictions to draw definite conclusions about the associations between students' depictions and their responses to the interview questions. Another study that compared each student's response to the question 'are you a computer-type person' with the number of stereotypical characteristics that the students depicted would tell us more about how perceptions of computer users relate to students' own engagement with technology.

These studies were conducted in the Silicon Valley region of Northern California, where many of our participants have exposure to a large number of the latest technologies and know family members and friends who work in technology-related industries. Although the data are drawn from schools that represent a broad range of socio-economic backgrounds, care should be taken when generalizing the results to students with fewer technological experiences. A replication of the study in other locations is an important next step for this project.

With these limitations in mind, it is the case that as we hypothesized, the relationship between gender and technology is more complex than a simple divide along gender lines, and we see more variation within each gender than between genders in level of engagement and experience. While there is clear evidence for a male stereotype, we did not find a gender difference in those who see themselves as computertype people. There does not seem to be a bias towards male engagement in technology that Mead and Métraux (1957) would have expected, and certainly not the level of difference that Camp (1997) or the Organization for Economic Co-operation and Development (2002) have reported. However, the existence of a male stereotype in the depictions highlights the importance of continued attention to gender differences in technology use and participation in formal courses that emerge during the middle- and high-school years. Most importantly, the change across grade levels in the proportion of females depicted should be a cause for concern and further study. 
Our results clearly show that middle-school students' engagement in technology is a complex relationship between students' experiences, their perceptions about others who are engaged in the field, and their personal identity in relation to the field, reiterating the importance of thinking about students' learning ecologies when we consider issues of engagement. These findings have implications for the wider educational community, echoing researchers who stress the importance of understanding the relationships between students' identities, their goals, and their achievement behaviours across domains (e.g. Markus \& Nurius 1986; Nasir 2002).

\section{Acknowledgements}

This work was supported by grants, to the second author, from the National Science Foundation (NSF REC 0354453, NSF REC 0238524), the Iris Litt Foundation and by the International Collaborative Education Foundation. Any opinions, findings and conclusions expressed in the paper are those of the authors and do not necessarily reflect the views of the sponsoring agencies. We would like also to thank all of the teachers and students who have contributed to this research.

\section{Appendix A Survey items}

Fluency Building Items

How often have you done these activities? (Never to more than 6 times)

Written code using a programming language like C, Java, Logo, Perl.

Started your own newsgroup or discussion group on the internet.

Hand-coded a web page using HTML.

Made a database.

Created a piece of music.

Made a publication such as a brochure or newspaper using a desktop publishing program like PageMaker or Word.

Designed a 2-d or 3-d model or drawing using a tool like CAD or Modelshop.

Built a robot or created an invention of any kind using technology.
Published a site on the web so other people could see it.

Created a website using an application like Dreamweaver or FrontPage.

Created a multi-media presentation.

Created a digital movie.

Created an animation or cartoon.

Created a computer game using software like GameMaker or through a programming language.

Created a piece of art using an authoring tool like PhotoShop or PaintShop.

Used a simulation to model a real life situation or set of data.

Engagement in Learning Scale

How much do you agree with these statements? (agree strongly to disagree strongly)

I would like to learn more about computers.

It is important to me that I am knowledgeable about computers.

Learning about what computers can do is fun.

I like the idea of taking computer classes.

Computers are interesting to me.

Confidence Scale

How much do you agree with these statements? (agree strongly to disagree strongly)

I feel confident about my ability to use computers. I am the kind of person who works well with computers.

I am good with computers.

Teaching others item

Are you teaching or helping anyone learn about computers? Yes/No 
Appendix B Table B1. Coding examples for depictions of someone who is knowledgeable about computers.

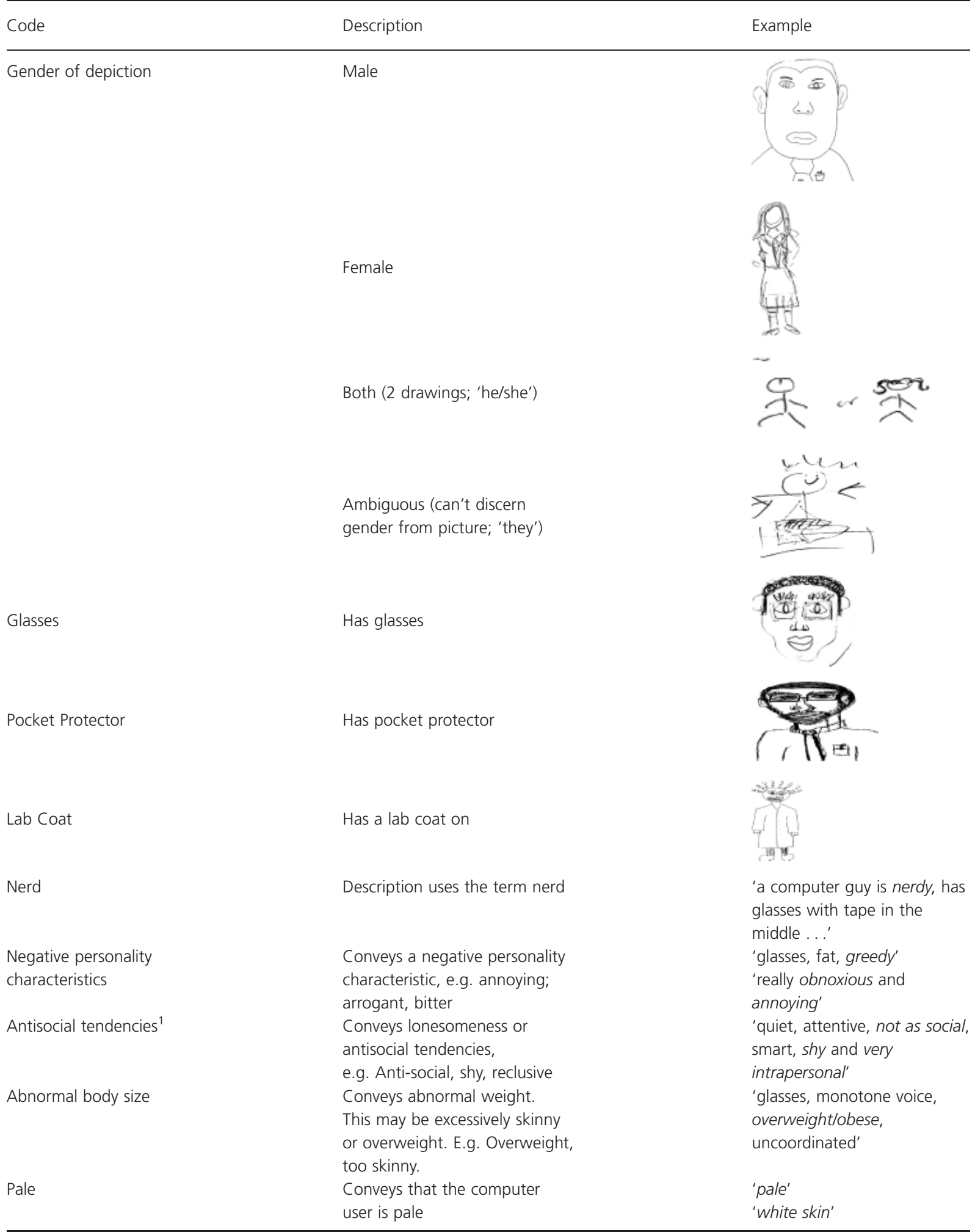

${ }^{1}$ For analysis purposes, negative personality characteristics and antisocial tendencies were collapsed to form a single variable, negative social characteristics. 
Appendix C Table C1. Coding examples for responses to interview questions.

\begin{tabular}{|c|c|}
\hline Response code & Examples \\
\hline \multicolumn{2}{|c|}{ Question: 'What is a computer-type person?' } \\
\hline Knows a lot about & 'He knows everything about computers.' \\
\hline computers & 'Maybe a person that knows more of computers and maybe sometimes they know how to build.' \\
\hline Spends a lot of time using & 'They go on the computer a lot.' \\
\hline computers & 'Once he comes home from work he just spend most of his time on computers working on stuff.' \\
\hline Loves computers & 'They really are into computers...' \\
\hline & 'Likes computers and knows a lot about them.' \\
\hline \multicolumn{2}{|c|}{ Question: 'Are you a computer-type person?' } \\
\hline Yes & $\begin{array}{l}\text { 'Yeah, in the sense that I can do almost any operation I want on it.' } \\
\text { 'Yeah. I'm involved with computers.' }\end{array}$ \\
\hline Maybe & $\begin{array}{l}\text { 'Not really, kind of ... but I like doing computers but I'm not like a nerd about it.' } \\
\text { 'Sometimes. Sometimes I'm on the computer and I don't know what to do.' }\end{array}$ \\
\hline No & $\begin{array}{l}\text { 'Not really. I know a lot about it just from my dad, but it just doesn't seem to fit me.' } \\
\text { 'No. I barely use the computer.' }\end{array}$ \\
\hline
\end{tabular}

\section{References}

American Association of University Women Educational Foundation (1999) Tech-Savvy: Educating Girls in the Computer Age. AAUW, Washington, DC.

Ashmore R.D. \& Del Boca F.K. (1981) Conceptual approaches to stereotypes and stereotyping. In Cognitive Processes in Stereotyping and Intergroup Behavior (ed. D.L. Hamilton), pp. 1-35. Erlbaum, Hillsdale, NJ.

Barba R.H. \& Mason C.L. (1994) The emergence of the "nerd": an assessment of children's attitudes towards computer technologies. Journal of Research on Computing in Education 26, 382-390.

Barron B. (2004) Learning ecologies for technological fluency: gender and experience differences. Journal of Educational Computing Research 31, 1-36.

Barron B. (in press) Interest and self-sustained learning as catalysts of development: a learning ecologies perspective. Human Development, in press.

Barron B., Martin C., Mercier E., Pilner K., Mathias A., Johri A. \& Walter S. (2003) Patterns of participation in fluency-building experiences in a high-tech community: Implications for bridging divides by design. Presented at the Annual Meetings of the American Educational Research Association, Chicago, IL, April 2003.

Barron B., Martin C \& Roberts E. (in press) Sparking self-sustained learning: report on a design experiment to build technological fluency and bridge divides. International Journal of Technology and Design Education, in press.

Brosnan M.J. (1999) A new methodology, an old story? Gender differences in the "draw-a-computer-user" test.
European Journal of Psychology of Education 14, 375-385.

Camp T. (1997) The incredible shrinking pipeline. Communications of the ACM 40, 103-110.

Chambers D.W. (1983) Stereotypic images of the scientist: the Draw-A-Scientist Test. Science Education 67, 255-265.

Fiske S.T. (1998) Stereotyping, prejudice and discrimination. In The Handbook of Social Psychology, 4th edition eds (D.T. Gilbert, S.T. Fiske \& G. Lindzey), pp. 357-411. McGraw-Hill, New York.

Goodenough F.L. (1926) Measurement of Intelligence by Drawings. Harcourt Brace, New York.

Greenwald A.G. \& Banaji M.R. (1995) Implicit social cognition: attitudes, self-esteem, and stereotypes. Psychological Review 102, 4-27.

Harris D.B. (1964) Children's Drawings as Measures of Intellectual Maturity: A Revision and Extension of the Goodenough Draw-A-Man Test. Harcourt, Brace World, Oxford, UK.

Jagacinski C.M., LeBold W.K. \& Salvendy G. (1988) Gender differences in persistence in computer-related fields. Journal of Educational Computing Research 4, 185-202.

Knight M. \& Cunningham C. (2004) Draw an engineer test (DAET): development of a tool to investigate students' ideas about engineers and engineering. ASEE Annual Conference Proceedings, 4079-4089.

Lazowska E. (2002) Pale and male: 19th century design in a 21st century world. SIGCSE Bulletin 34, 11-12.

Markus H. \& Nurius P. (1986) 'Possible selves'. American Psychologist 41, 954-969. 
Margolis J. \& Fisher A. (2002) Unlocking the Clubhouse: Women in Computing. MIT Press, Cambridge, MA.

Mead M. \& Métraux R. (1957) Image of the scientist among high-school students. Science 126, 384-390.

Nasir N.S. (2002) Identity, goals and learning: mathematics in cultural practice. Mathematical Thinking and Learning 4, 213-247.

National Research Council (1999) Being Fluent with Information Technology. National Academy Press, Washington, DC.

O’Maoldomhnaigh M. \& Mhaolain V.M. (1990) The perceived expectation of the administrator as a factor affecting the sex of scientists drawn by early adolescent girls. Research in Science and Technological Education 8, 69-74.

Organization for Economic Co-operation and Development (2002) Education at a Glance: OECD Indicators 2002. OECD Publication Services, Paris.
Packard B.W. \& Wong E.D. (1999) Future Images and Women's Career Decisions in Science. Access ERIC, FullText, MI.

Sackrowitz M. \& Princeton Univ., NJ. Mid-Career Fellowship Program (1995) An Unlevel Playing Field: Women in the Introductory Computer Science Courses. Access ERIC, FullText, NJ.

Schott G. \& Selwyn N. (2000) Examining the "male, antisocial" stereotype of high computer users. Journal of Educational Computing Research 23, 291-303.

Steele C.M. (1997) A threat in the air: how stereotypes shape intellectual identity and performance. American Psychologist 52, 613-629.

Teague J. (2002) Women in computing: what brings them to it, what keeps them in it? SIGCSE Bulletin 34, $147-158$

Warschauer M. (2003) Demystifying the digital divide. Scientific American 289, 42-47. 